Proc. Indian Acad. Sci. (Earth Planet. Sci.), Vol. 91, No. 1, March 1982, pp. 21-28. (c) Printed in India.

\title{
Geoelectrical soundings for the study of suitable aquifers in the Gangetic alluvium of Allahabad region
}

\author{
C L SINGH and G S YADAV \\ Department of Geophysics, Banaras Hindu University, Varanasi 221 005, India \\ MS received 13 April 1981; revised 2 September 1981
}

\begin{abstract}
Sixteen geoelectrical soundings were taken in the western part of the district Allahabad lying between the rivers Ganga and Yamuna during the month of April 1976. The area of investigation forms the eastern part of Doab of rivers Ganga and Yamuna. Schlumberger configuration of geoelectrical soundings was used and the data were interpreted mainly by curve matching technique and theoretically calculated multi-layer model curves. Based on the results of the investigation it has been possible to draw geoelectrical section along two profiles and prepare a contour map of resistant substratum representing the base of the alluvial cover. A fence diagram has been constructed to represent the result of all the sounding data. The results of the present geophysical study have provided valuable information regarding the subsurface geology of this virgin area and also the potential aquifer zones which could be exploited for regular supply of groundwater for irrigation and drinking purposes.
\end{abstract}

Keywords. Geoelectrical sounding; aquifers; Schlumberger confguration; resistant substratum; fence diagram.

\section{Introduction}

The results of geophysical investigation carried out for the location of suitable aquifer in Allahabad region are discussed in this paper. The effectiveness of the resistivity sounding in locating potential aquifers and in minimizing drilling costs is well established. The important aspect of this study is to estimate the thickness of alluvial cover and aquifer zones in the eastern part of the Doab, about which no authentic information is available so far except a few shallow boreholes. The area covered, is situated in the west of the confluence of the rivers Ganga and Yamuna. The area surveyed extends in the west to Sarai-Akil town about $35 \mathrm{~km}$ from Allahabad city. The Vindhyan sediments exposed further south of the river Yamuna are expected to be present immediately below the alluvium. The interpretation of the field curves was checked and improved by modelling the results on a digital computer using a program based on the nine-point digital linear filter (Ghosh 1971). The results of vertical electrical sounding have helped in the estimation of alluvial thickness and location of suitable aquifers. Vertical distribution of aquifer is represented in the form of fence diagram (figure 3). A contour map is prepared, showing the configuration of resistant substratum which is expected to be the extensions of Vindhyan sandstone exposed in the south within about $3 \mathrm{~km}$ of the area of investigation (figure 1). 


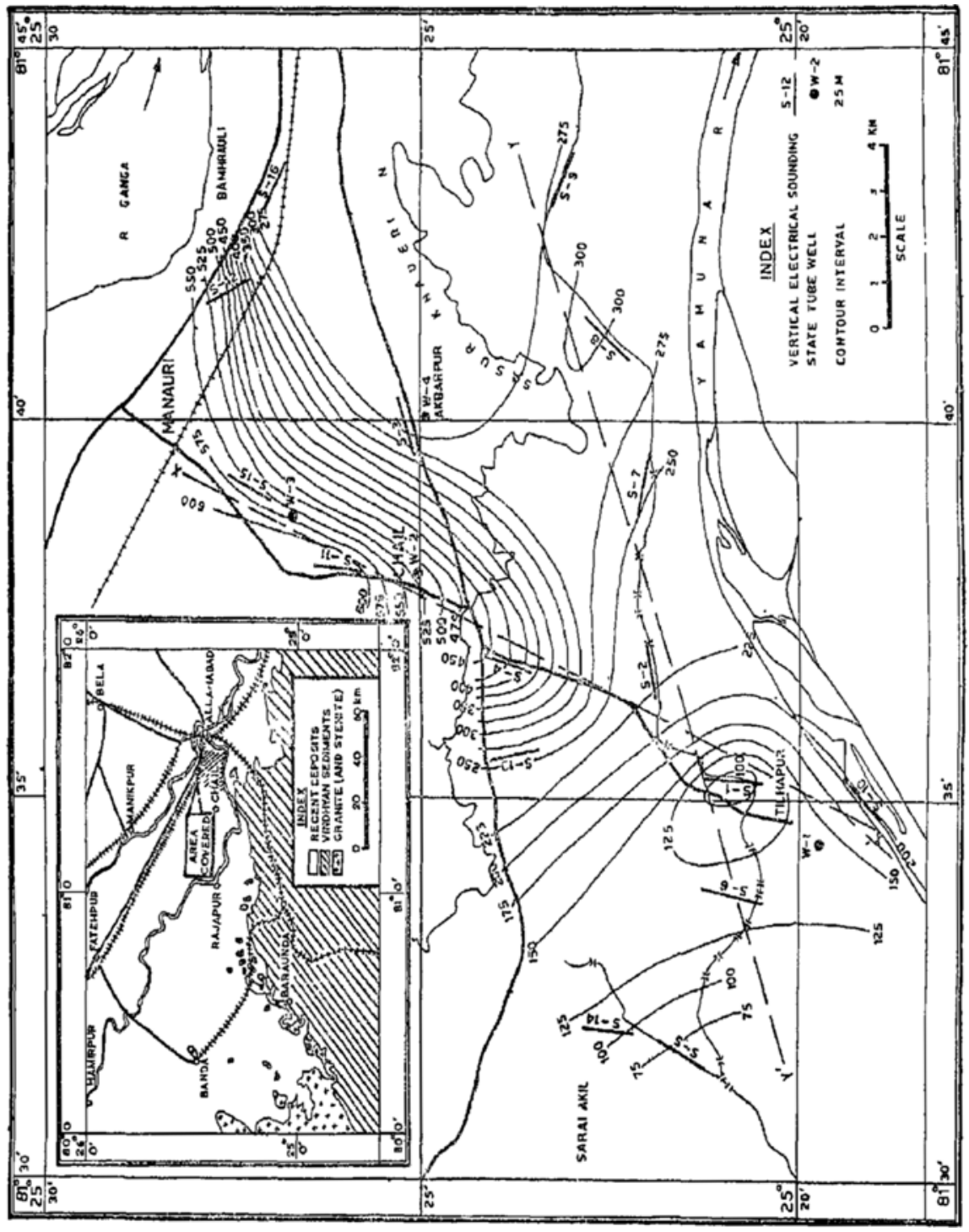

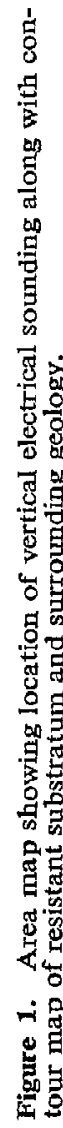




\section{Geology and geohydrology}

The area under investigation is the part of Ganga-Yamuna Doab represented by monotonously flat plain except some undulations in the vicinity of the rivers Ganga and Yamuna which form the main drainage system of the area. It is situated between latitude $25^{\circ} 22^{\prime}$ to $25^{\circ} 30^{\prime}$ and longitude $81^{\circ} 30^{\prime}$ to $81^{\circ} 50^{\prime}$ in district Allahabad (U.P.). The area forms the part of central Gangetic alluvial plain. The Vindhyan formation is concealed under thick alluvial cover. The whole of transGanga track, the greater portion of Doab is composed of Gangetic alluvium. The lithological information of the alluvial track is available only through shallow wells drilled for irrigation purposes. The alluvium is composed mainly of gravel, sand, silt, clay and kankar. The beds are generally lenticular and there are rapid alterations and gradations between granular and clay horizons. The Vindhyan sediments and Bundelkhand granites (Krishnan and Swaminathan 1959), exposed further south of the area are expected to be present below the alluvium and form the bedrock.

The presence of sandy-clay soil cover near the surface are expected to provide better condition for infiltration and consequently the recharge of the groundwater. The area experiences extreme climatic conditions being cold during winter and very hot during summer. The variation of temperature from winter to summer is normally between $15^{\circ} \mathrm{C}$ to $45^{\circ} \mathrm{C}$. The area receives the average rainfall of $976 \mathrm{~mm}, 80 \%$ of which falls during monsoon period, i.e. July to September. The precipitation is the main source for recharge of groundwater and about $25 \%$ of total precipitation is expected to contribute towards it. Due to concentration of rainfall during monsoon period a major portion of it goes as runoff (about $40 \%$ ) and the rest is taken as evapotranspiration. The depth of the water table varies between $6 \mathrm{~m}$ to $12 \mathrm{~m}$ with seasonal variation of about $4 \mathrm{~m}$. The value of porosity, permeability and specific yield of the alluvial deposits of the area is expected to vary locally depending on size, sorting, shape, packing and incipient cementation of particles. In general, the alluvial track of middle Gangetic plain forming lower ridge of Doab of rivers Ganga and Yamuna with their tributaries are considered to be the prolific source of groundwater (Baweja 1980).

\section{Method of investigations}

Sixteen vertical electrical soundings were taken at suitable intervals using the quadrupole Schlumberger array. D. C. resistivity meter manufactured by National Geoplysical Research Institute, Hyderabad was used. Electrode separation from $600 \mathrm{~m}$ to $1200 \mathrm{~m}$ was kept depending upon the requirement and accessibility of the area.

Ebert's (1943) method of auxiliary point was applied in this study to interpret multi-layer field curves with a set of three layer master curves (Orellana and Mooney 1966; Rijkswaterstaat 1969). Accuracy of interpretation was checked by estimating the total longitudinal conductance (Keller and Frischknecht 1966) for curves showing infinite resistivity for the last layer.

Parameters obtained by Ebert's method were utilized to compute the multi-layer resistivity sounding curves using digital linear filters (Ghosh 1971) on a DEC system10 digital computer. For better accuracy the interpretation obtained by curve 
matching, has been modified as a result of theoretical computation of apparent resistivity curve.

\section{Results and discussions}

As discussed earlier, all the sounding data were interpreted both by curve-matching and digital linear filter techniques (Ghosh 1971). For illustration, a typical example of vertical electrical sounding, ' $\mathrm{S}-3$ ', is presented in figure 2. A fairly good match has been obtained by three layer partial curve matching technique. However, when the layer parameters obtained by curve matching technique are used to compute the theoretical apparent resistivity curves by linear filter, there is a shift in the apparent resistivity curve. This type of error in the curve matching technique was rectified by introducing suitable variation in the layer parameter while calculating the theoretical curves. All the three types of interpretation are represented in the figure. Depth sections of the interpreted layer parameter as well as borehole data from state tubewell, 'W-4 ', village Akbarpur, in the vicinity of vertical electrical sounding, 'S-3', are drawn to show the accuracy of the interpretation.

With the knowledge of thickness and resistivity of the various layers as obtained from the interpretation of sounding data, the depth of the resistant substratum has

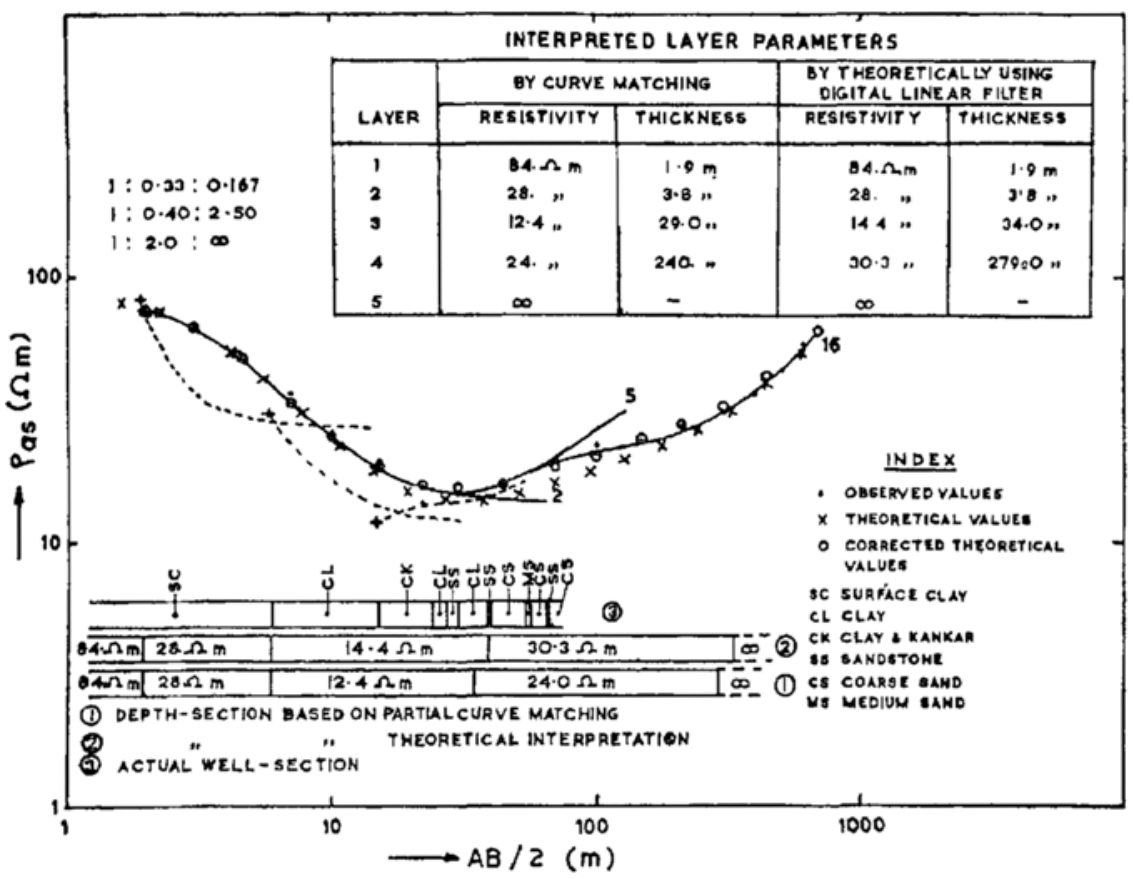

Figure 2. Illustration of interpretation by partial curve matching and theoretically computed values and their correlation with actual well-data. 
been estimated. This has heiped in preparing a contour map indicating the thickness of the alluvium (figure 1). Sudden increase in the thickness of alluvial cover is quite significant in the north-western side of the area. Such good thickness of alluvium with sandy formation is expected to form prolific source of groundwater.

A fence diagram has been prepared to represent the results of all the sounding data along with their correct sounding position in the area and corresponding layer distribution in the vertically downward direction (figure 3). This brings out clearly, the lithological changes within the alluvial cover and presents an areal view of the subsurface geology. The development of sand formations in the vicinity of the rivers Ganga and Yamuna stands out prominently. Variation in the thickness of alluvial cover can be visualized at a glance with an increase from WSW to ENE. The increase in the thickness is rather sudden in the vicinity of the river Ganga.

Based on the results as obtained from the interpretation of the sounding curves and a few borehole data, two geoelectrical cross-section, i.e. $X-X^{\prime}$ (NNE-SSW) and $Y-Y^{\prime}$ (ENE-WSW) along with their respective sounding curves are shown in figure 4 and figure 5, respectively.

Profile $X-X^{t}$ (in NNE to SSW direction) incorporates the result of resistivity sounding right from the bank of river Yamuna in the south upto very close to river Ganga in the north. The change in the lithological character of the alluvial cover is quite revealing. A thin clayey section with varying thickness near the surface is present along the profile. Below this clayey section, deposition of sandy horizon in the vicinity of these rivers is quite prominent with increasing admixture of clayey soil away from the major channels. This is very well confirmed from the strata chart of

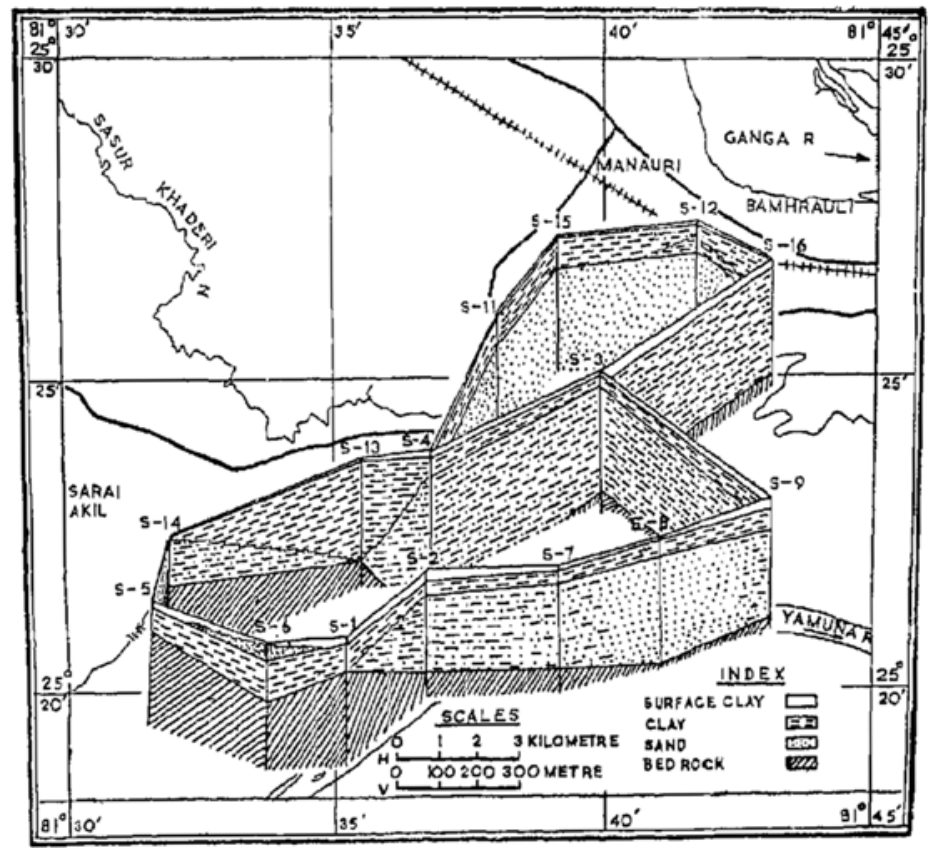

Figure 3. Fence diagram showing the water bearing zones upto $300 \mathrm{~m}$ depth. 
the borehole shown in the profile at appropriate locations. The resistant substratum, is expected to be an extension of the Vindhyan sandstone which is exposed within 3 $\mathrm{km}$ in the south of the area, indicates rising trend towards the north from the river Yamuna (vertical electrical sounding, ' $\mathrm{S}-10$ ') for about $2 \mathrm{~km}$ and then it slowly goes down, further north. This has resulted in good thickness of alluvial deposit with increase in the sand percentage towards the river Ganga. Such thick sand deposit is expected to form a very good source of groundwater.

Profile $Y-Y^{\prime}$ (in ENE to WSW direction) in the Doab area is rather close to the river Yamuna on the western side of the profile. There is hardly any change in the near surface clayey horizon except that in the vicinity of vertical electrical sounding ' $S-6$ ', there is a thin section of sand deposit above the clayey formation. In this profile second layer appear only on the east of vertical electrical sounding, 'S-1', with little change in its thickness. There appears gradual increase in the sand content of the bed towards the east which can be attributed due to river Ganga. The resistant substratum indicating infinite resistivity is expected to be a rather consolidated Vindhyan formation exposed in the southern part of the area.

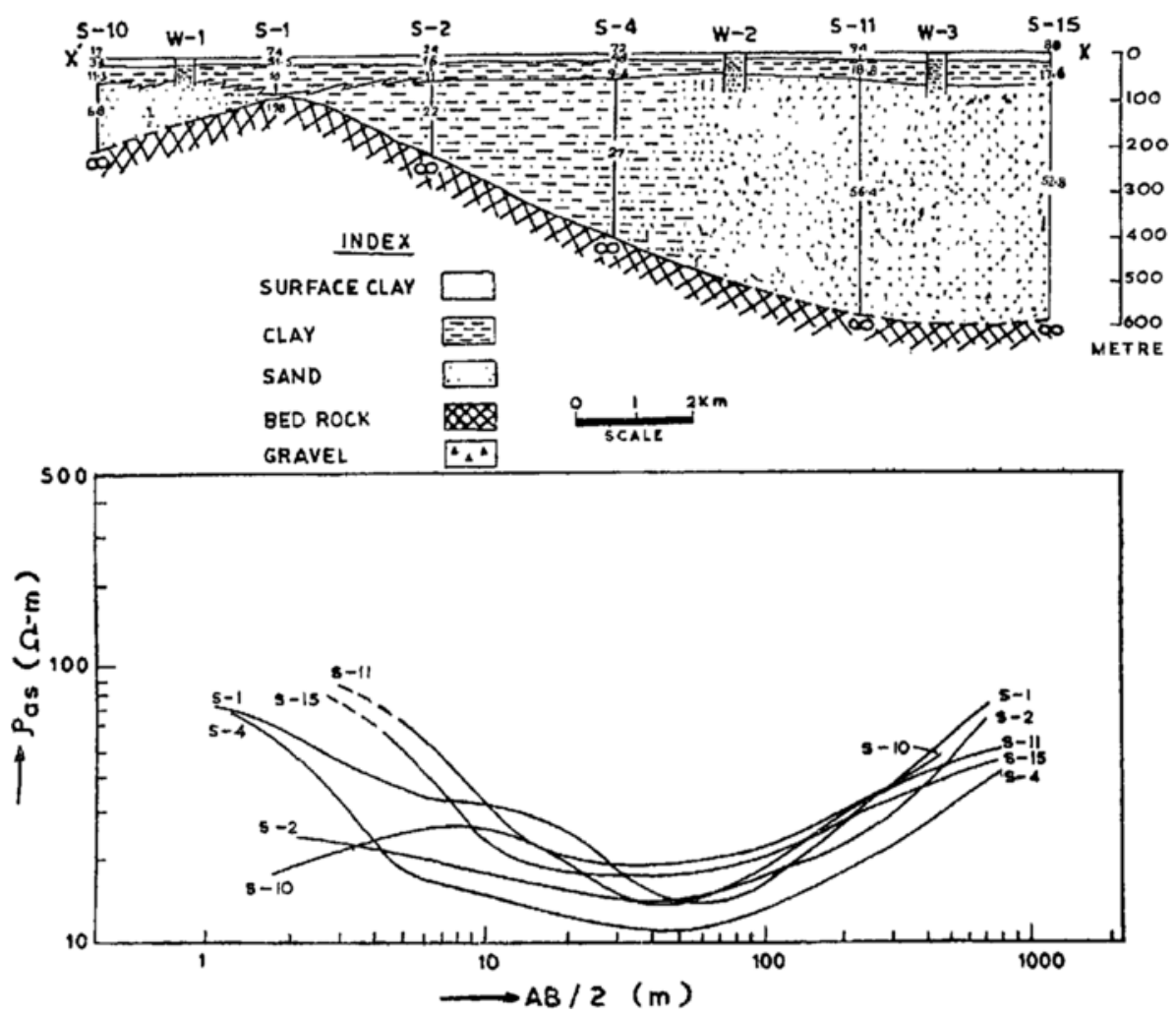

Figure 4. Geoelectrical cross-section $X-X^{\prime}$ along with their respective sounding curves. 


\section{Conclusion}

The results of the geoelectrical sounding, presented in the form of geoelectrical crosssections and fence diagram give valuable information in respect of liothlogical changes, sub-surface geology and areal distribution of aquifers. With the maximum separation of $1.2 \mathrm{~km}$ between current electrodes as used in the present investigation, it could not be possible to reach the resistant substratum in the deeper part of the alluvium. The present investigation has provided reliable information in respect of suitable aquifers of the area as confirmed from the existing borehole data. Surface resistivity survey is expected to form one of the basic tools for future exploration and development of sub-surface water resources of the Ganga-Yamuna Doab area. The application of geoelectrical sounding on the Gangetic alluvium of Doab region, proved to be very useful in extending the hydrogeologic knowledge of the area.

\section{Acknowledgement}

The authors are grateful to the Department of Geophysics, Banaras Hindu University, for providing facilities in conducting the field work. They are also thankful to the Head, Computer Centre, IIT, Kanpur, for his help and co-operation in computations.

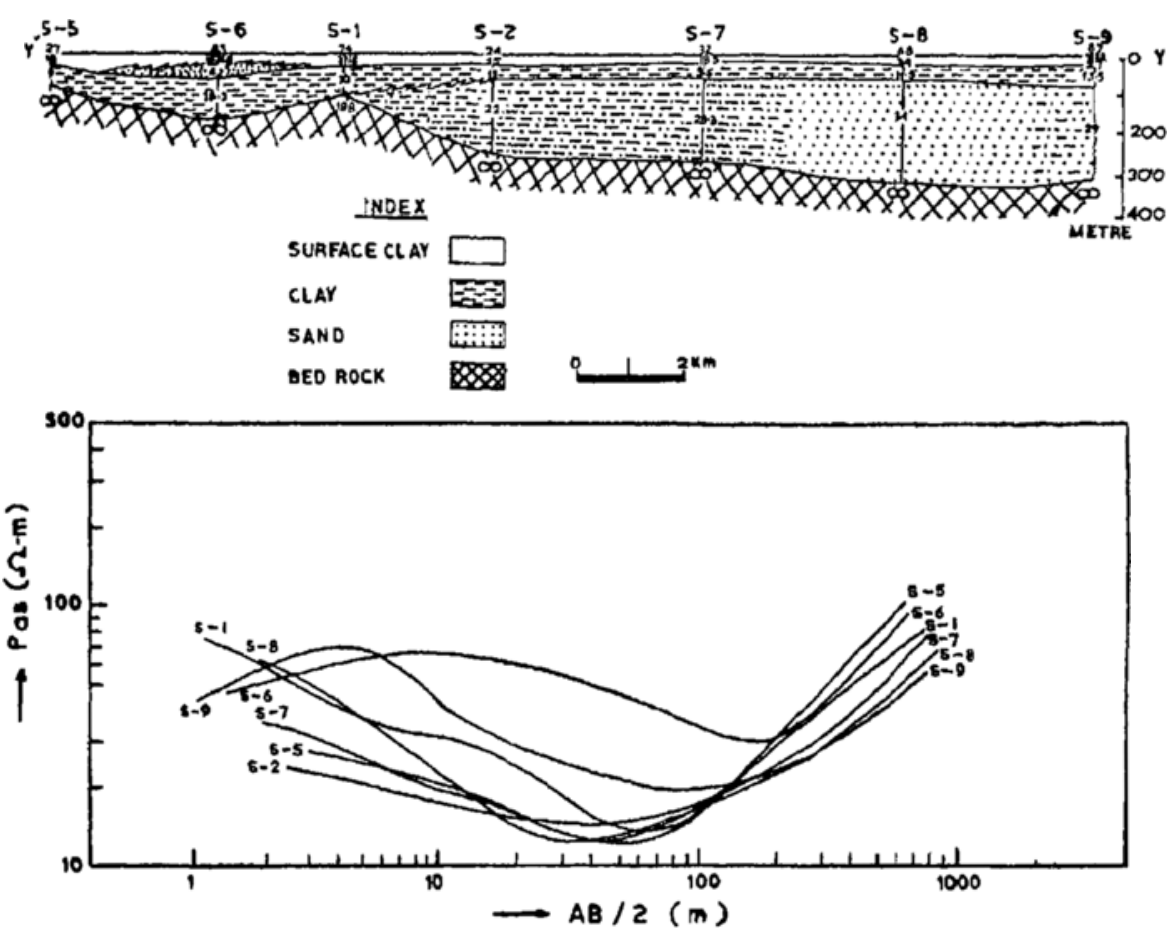

Figure 5. Geoelectrical cross-section $Y-Y^{\prime}$ along with their respective sounding curves. 


\section{References}

Baweja B K 1980 Hydrogeological setup and groundwater resource potential of India, Bull. 3 (Technical Series-H)

Ebert A 1943 Geophysics 101

Ghosh D P 1971 Geophys. Prospect. 19769

Keller G V and Frischknecht F C 1966 Electrical methods in geophysical prospecting (Pergamon Press)

Koefoed O 1979 Geosounding principles 1, Resistivity sounding measurements (Elsevier)

Krishnan M S and Swaminathan J $1959 \mathrm{~J}$. Geol. Soc. India 110

Oreilana E and Mooney H M 1966 Master tables and curves for vertical electrical sounding over layered structures (Madrid, Spain: Interciencia)

Rijkswaterstaat 1969 Standard graph for resistivity prospecting prepared by Van Dam and Mouleakemp (EAEG) 